ORIGINAL ARTICLE

\title{
The estimation scale of the daily pedometry of senior students
}

\author{
Mikhail M. Kolokoltsev ${ }^{1 \mathrm{ABCDE}}$, Elena V. Romanova ${ }^{2 \mathrm{BCDE}}$, Wladyslaw Jagiello ${ }^{3 \mathrm{CDE}}$, Tetiana S. Yermakova ${ }^{4 \mathrm{CDE}}$ \\ ${ }^{1}$ Irkutsk National Research Technical University, Russia \\ ${ }^{2}$ Altay State University, Russia \\ ${ }^{3}$ Gdansk University of Physical Education and Sport, Poland \\ ${ }^{4}$ Kharkiv State Academy of Design and Arts, Ukraine
}

Authors' Contribution: A - Study design; B - Data collection; C - Statistical analysis; D - Manuscript Preparation; E - Funds Collection.

\begin{abstract}
Purpose: $\quad$ To create the estimation scale of the daily pedometry of senior students with different levels of motor activity. To determine the dependence of students' life quality on the volume of step locomotions.

Material: $\quad$ The students of Irkutsk National Research Technical University (Irkutsk, Russia) $(n=235$ : females $-n=78$, males $-\mathrm{n}=157$ : 19-20 years old) participated in the study. The daily pedometry of students for 7 days was studied. The number of daily steps was recorded by Simple Design Ltd application for smartphones. The sigma deviation method was used to develop an individual daily pedometry estimation scale. The daily pedometry scale was developed based on the distribution of this characteristic by 5 sigma classes ("low", "below average", "average", "above average", "high"). Students' life quality was studied using a Russian-language version of SF36 (Short Form Health Survey). The survey presents the characteristics of physical (PH), mental (MH) and general $(\mathrm{GH})$ health. The answers were estimated in points (0-100).

Results: $\quad$ Most students have an "average" level of step locomotions. 10\% of males and about $8 \%$ of females have "above average" or "high" pedometry level. This group of students is actively engaged in sports activities. $4.8 \%$ of males and $7.5 \%$ of females have a "low" pedometry level. In this group of students, motor activity is limited only by locomotions related to educational and household activities. Students with "high" and "above average" pedometry levels have the highest values of life quality indicators. Such students are in a safe zone of non-communicable diseases. The "low" level of daily step locomotions is considered as a predictor of insufficient physical activity, low general and mental health of students.

Conclusions: The sigma deviation method allows distributing any population of people by the number of daily locomotions into five sigma classes. The level of daily step locomotions can be considered as a marker of physical activity, general and mental health. This approach makes it possible to refer a person to a safe health zone or a risk group of non-communicable diseases. The results of the study can be used in the recommendations for improving the students' life quality. It is also recommended to use our recommendations to increase students' self-motor activity during their university studies.

Keywords: motor activity, step locomotions, daily locomotions, life quality.
\end{abstract}

\section{Introduction}

The important condition for the harmonious development of an individual is his regular motor activity. This is especially important in adolescent ontogeny. The term "physical activity" includes the total value of various human movements over some time [1]. In the last decade in Russia [2] and foreign countries [3-5] there is an expressed hypokinesia of students against the learning process complication and computerization [6].

The decrease in student health indicators [7] is due to: the influence of psycho-emotional factors in learning; increased time for self-training; diet violation [8]; significant spread of social-negative phenomena in the youth environment [9-11].

One of the effective ways of overcoming hypokinesia is cyclic physical activity in the form of locomotions [12]. This allows compensating for the deficit of the students' motor activity. This is especially important in senior courses because such students no longer have obligatory physical education classes. In the scientific literature, (c) Mikhail M. Kolokoltsev, Elena V. Romanova, Wladyslaw Jagiello,

Tetiana S. Yermakova, 2020

doi:10.15561/20755279.2020.0205 there are actual discussions on the normalization of the required number of steps in the daily physical activity of students [13].

The motor activity can be expressed in energy consumed units or the number of performed movements (locomotions). The objective and unified method for a person's motor activity estimation is pedometry [14-16].

The literature gives various recommendations on the daily step locomotions performance by a person: not less than 10 thousand [17] or 14-19 thousand steps per day [18]. It is proposed the standards of 20-25 thousand steps per day for females and 25-30 thousand steps for males [19]. Such a significant variation of the recommended norm of daily pedometry is explained by the authors as the body specifications of each individual. The influence of genetic factors on the motor potential of a particular person has been experimentally proved [20]. It is determined the features of the influence of natural and climatic and environmental [21], social and household [17] and other factors on the morphofunctional development and motor activity of people. According to the authors' opinion, the volume estimation of the daily motor activity of a person 
by average standards is not correct enough [22].

The sigma deviation method is used to characterize the studied indicator by the levels of distribution. This method is widely used in biomedical research to evaluate the physical development of Russian children [23, 24] and ecological situation in the territories of the population [25]. It is also used in clinical practice to predict the risk of cardiovascular pathology developing in the form of a Z-score modification [26].

We have not found any studies devoted to the use of the sigma deviation method for the development of individual daily pedometry assessment scales. This approach considers gender, age, place of birth and residence of the studied contingent. These studies are considered to be promising.

The methods of studying health concerning human life quality (LQ) assessment have been widespread in recent years [27]. The international SF-36 (Short Form Health Survey) is used for this purpose [28]. This survey has been tested in many studies in different countries [29]. It allows determining the quantitative characteristic of human activity, ie. the condition of his physical, general and mental health.

The study of the correlation between locomotions (number of steps) and the life quality of university students is of scientific and practical interest.

The purpose of the study. To create the estimation scale of daily pedometry of senior students with different levels of motor activity. To determine the dependence of students' life quality on the volume of step locomotions.

Material and methods.

Participants. The students of Irkutsk National Research Technical University (Irkutsk, Russia) $(\mathrm{n}=235$ : females $-\mathrm{n}=78$, males $-\mathrm{n}=157$ : $19-20$ years old) participated in the study.

Design of the study. The daily pedometry survey and a survey on students' life quality were conducted in 2019 during a week. The surveys were conducted after the course "Optional Course in Physical Culture and Sports" completed by students.

The parallel pilot study of the number of students steps locomotions was conducted at the beginning of the work to select a valid method of recording the daily pedometry.

Two groups of students (20 people for each method) participated in the experiment. The daily volume of steps was recorded in the first group using the "OMRON HJ-005" pedometer and in the second group using Simple Design Ltd application for the smartphone. There was no significant difference between the results of daily pedometry measurement performed by the abovementioned methods ( $p>0.05$ ). The second method was chosen for the study. The advantage of this method is the availability and possibility of simultaneous mass examination of students. Also, this method needs no financial expenses. During the week, students recorded the number of daily steps and types of physical activity in the self-control diary.

The first stage of the study was to measure the average weekly number of student's steps. In the next stage, the possibility of using the sigma deviation method in the pedometry was considered. For this purpose, the normality of step locomotions' distribution was assessed according to the Kolmogorov-Smirnov criterion [30]. After confirming the normality of the sample distribution proceeded to the third stage - the calculation of sigma (standard deviation) by the formula:

$$
\sigma=\left[\left(x_{i}-\bar{x}\right)^{2} / n\right]^{-2}
$$

where, $x_{i}$ - is the $i^{\text {th }}$ element of the sample, $\bar{X}$ - is the arithmetic mean of the sample, and $n-$ is the volume of sample.

The fourth stage was to develop an estimation scale of individual step locomotions: it was determined sigma deviation from the arithmetic mean value and the level of the student's pedometry.

The results of each student were divided into 5 sigma classes (gradations): the criterion is an individual indicator of the number of steps per day. If the value of the indicator corresponded to the gradation $M \pm 0.67 \sigma$ - the level of pedometry was estimated as "average". In the gradation interval from $M \pm 0.67 \sigma$ to $M \pm 1.34 \sigma$, the level of pedometry was estimated as "above average" or "below average". If the value of the indicator was out the $\mathrm{M} \pm 1.34 \sigma$ graduation, then the student's pedometry level was estimated as "high" or "low".

The students' life quality was studied using a Russianlanguage version of the Short Form Health Survey (SF36) [28]. The survey has: 36 questions ( 8 scales) and includes characteristics of physical $(\mathrm{PH})$, mental $(\mathrm{MH})$ and general $(\mathrm{GH})$ health. The answers were estimated in points $(0-100)$. The higher is the points, the higher is the respondent's estimation of life quality.

The performed work does not limit the rights and endanger the well-being of the students following the ethics standards of the Committee on Experiments of the 2008 Helsinki Declaration [31].

Statistical analysis. The programs «Microsoft Excel», «StatSoft Statistica 6.1» were used in the study. The sample volume (n), mean (M), minimum, maximum, standard deviation $(\sigma)$, and standard error were estimated. The reliability of indicators' differences was determined by Student's parametric t-test. The MannWhitney U-criterion non-parametric method was used for comparing the results of two methods of parallel daily estimation the number of steps. The differences were considered significant at the level of $\mathrm{p}<0.05$ [30].

\section{Results.}

We created a scale of daily pedometry levels in the surveyed students using the sigma deviation method (Table).

The average daily number of step locomotions in males is $10.7 \%$ higher than in females $(8434.8 \pm 369.7$ and $7534.7 \pm 298.6$, respectively), $p<0.05$. The range of daily steps for males was from 2825 to 26830 , for females - from 2429 to 16725 . Fig. 1 presents the distribution of the number of students surveyed by levels of daily pedometry. 
Table. The estimation scale of the daily pedometry of senior students

\begin{tabular}{llll}
\hline \multirow{2}{*}{ Sigma class (gradation) } & Pedometry level & Number of steps & \\
\cline { 3 - 4 } & & Males & Females \\
\hline M low $-1,34 \sigma$ & Low & $<6248,2$ & $<5640,1$ \\
M from $-0,67$ to $-1,34 \sigma$ & Below average & $7341,5-6248,2$ & $6587,4-5640,1$ \\
$M \pm 0,67 \sigma$ & average & $7341,5-9528,1$ & $6587,4-8482,0$ \\
$M$ from $+0,67$ to $+1,34 \sigma$ & Above average & $9528,1-10621,4$ & $8482,0-9429,3$ \\
$M$ high $+1,34 \sigma$ & High & $>10621,4$ & $>9429,3$ \\
$M \pm m$ & & $8434,8 \pm 369,7$ & $7534,7 \pm 298,6$ \\
$\sigma$ & & 1631,8 & 1413,9 \\
\hline
\end{tabular}

Note. $\mathrm{M}$ is the arithmetic mean of the daily number of steps; $\sigma$ is the sigma (standard) deviation of the indicator

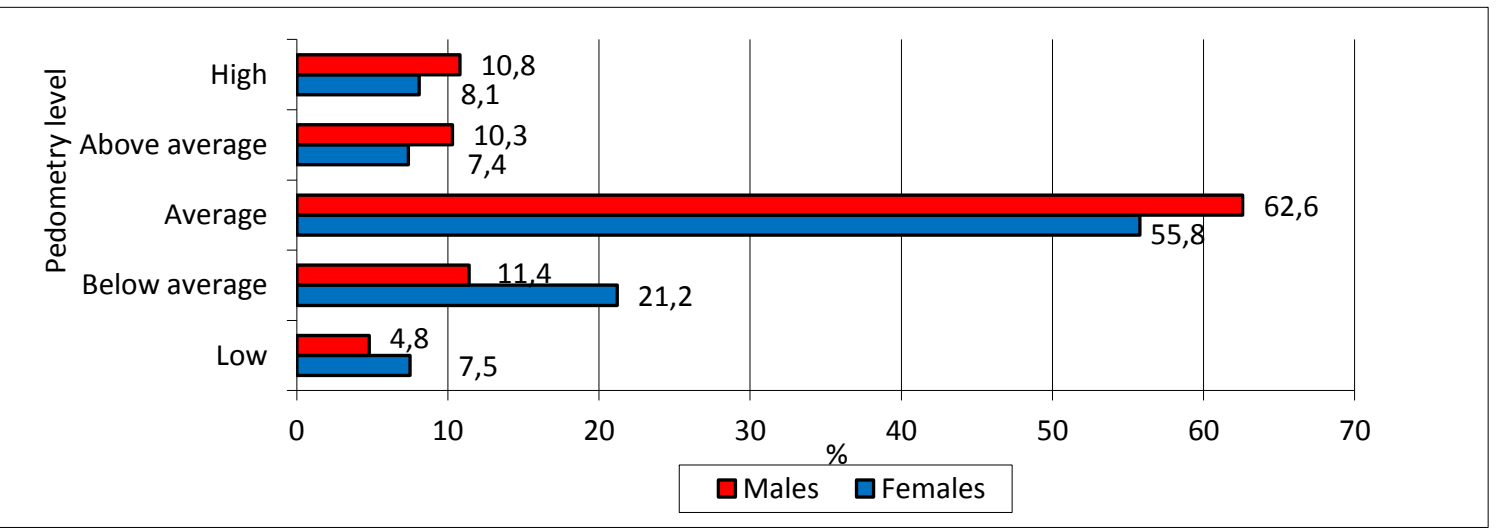

Figure 1. Number of senior students with different levels of daily pedometry (\%)

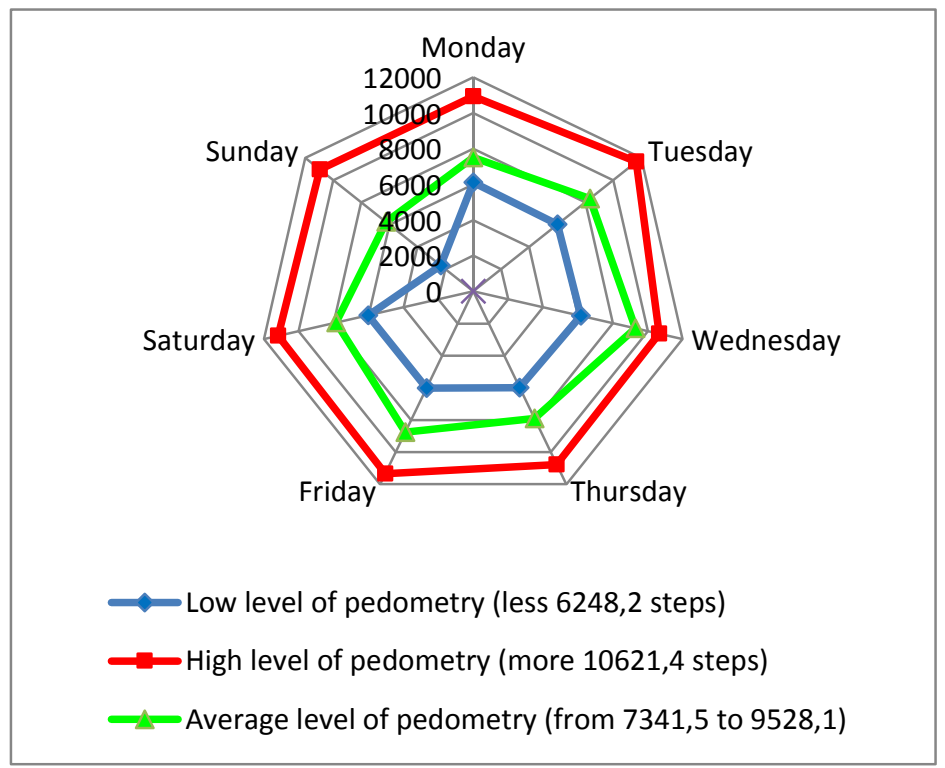

Figure 2. Distribution of the number of steps in males per day of the week

$4.8 \%$ of males and $7.5 \%$ of females have a "low" level of pedometry (Fig. 1). Females with a "low" level are $56.2 \%$ more than males. It was registered $11.4 \%$ of males and $21.2 \%$ of females with a pedometry level "below average". Moreover, the number of females with this level is $85.9 \%$ higher than males.

Most students have an "average" level of steps per day. And the females were $12.2 \%$ less than the males.
According to our study, $10 \%$ of males and about $8 \%$ of females have "above average" or "high" levels of pedometry. They are actively engaged in sports activities. The number of males exceeds the number of females.

Analysis of the students' weekly pedometry determined that the most interesting characteristics of the indicators were determined on Sunday (Fig. 2). 
The number of daily step locomotions in students with a "high" level of daily pedometry is approximately the same by day of the week (including Sunday) (Figs. 2, 3). These are mostly student-athletes.

Students with "low" levels of daily pedometry reduce the number of steps on Sunday days: in males by $61.6 \%$, in females by $77.3 \%$.

Students with an "average" level of pedometry the number of daily walking locomotives on Sunday days is reduced: by $24.7 \%$ in males and by $33.2 \%$ in females.

The characteristics of life quality (LQ) components of students with different levels of daily pedometry are presented in Figs. 4 (males), in fig. 5 (females).
Students with "high" and "above average" levels of daily pedometry have the highest level of physical activity, high points of mental and general health (Figs. 4, 5).

Males and females with "low" and "below average" levels of step locomotions have the lowest points of life quality components.

\section{Discussion}

At present time, the sigma deviation method of the studied indicator is used in scientific research: for the estimation of physical development of youth [23, 24]; in monitoring the ecological situation in the territories of the population [25]; in the prediction of the cardiovascular

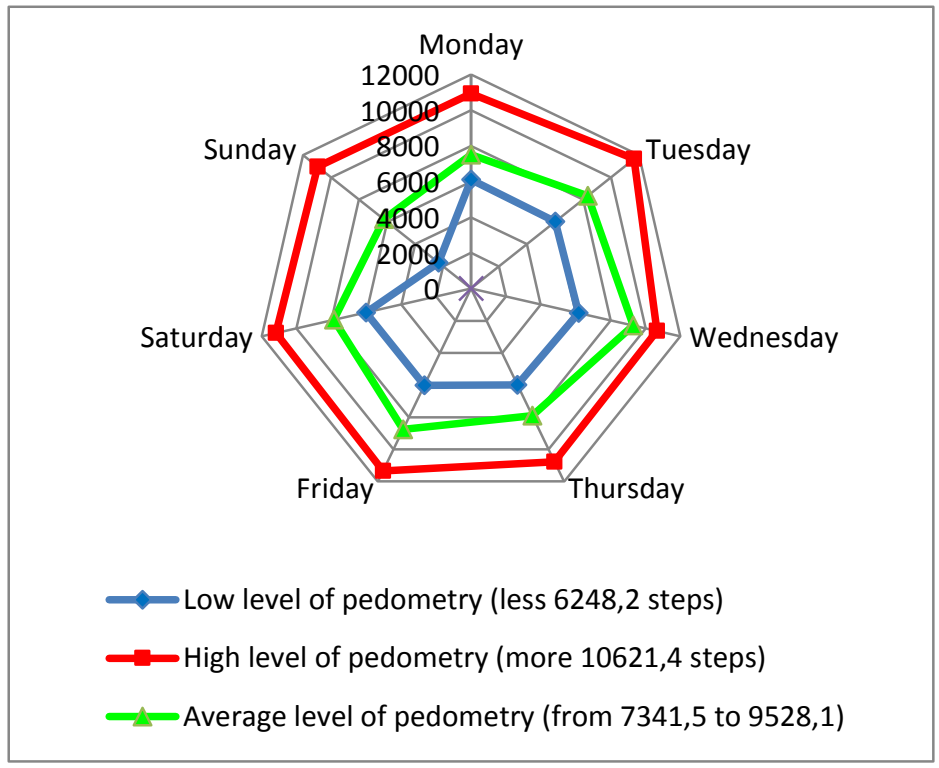

Figure 3. Distribution of the number of steps in females per day of the week

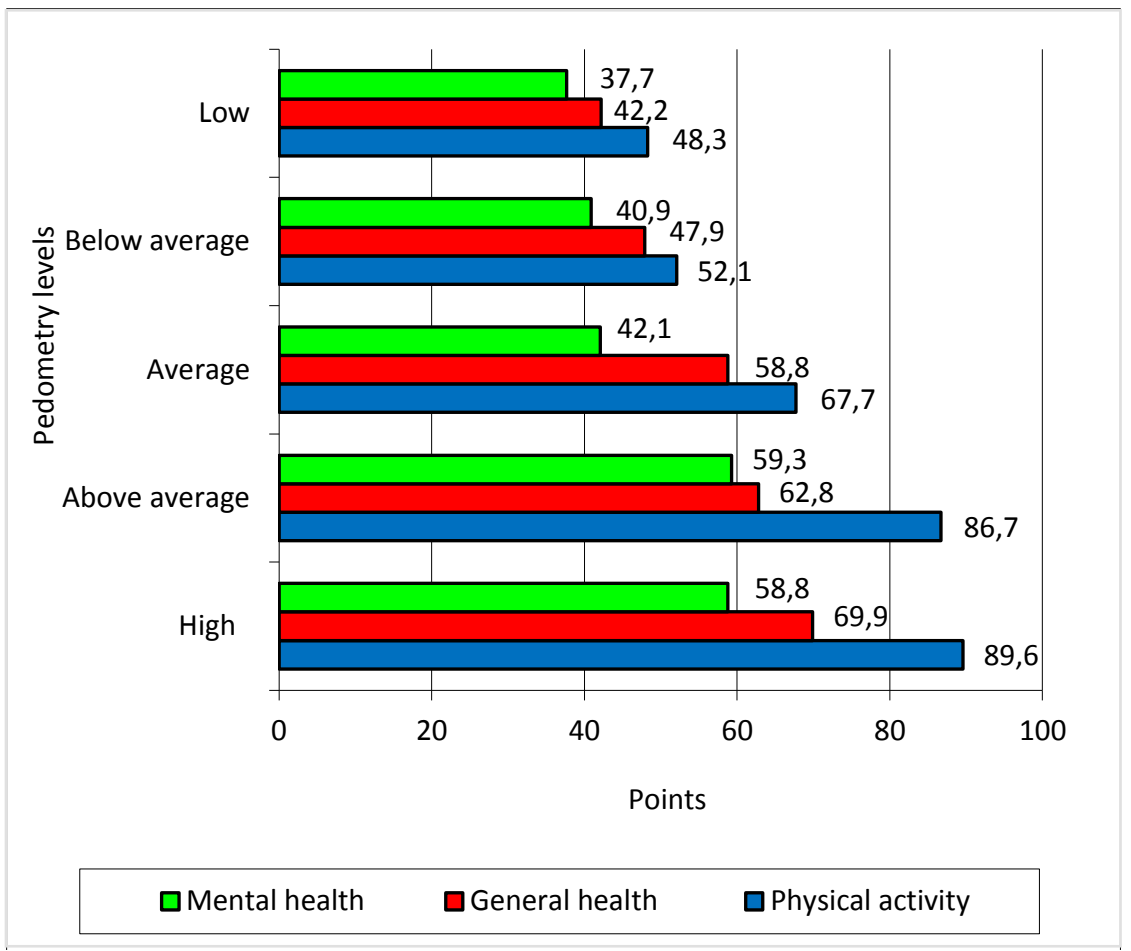

Figure 4. Life quality components of males with different levels of pedometry (in points) 


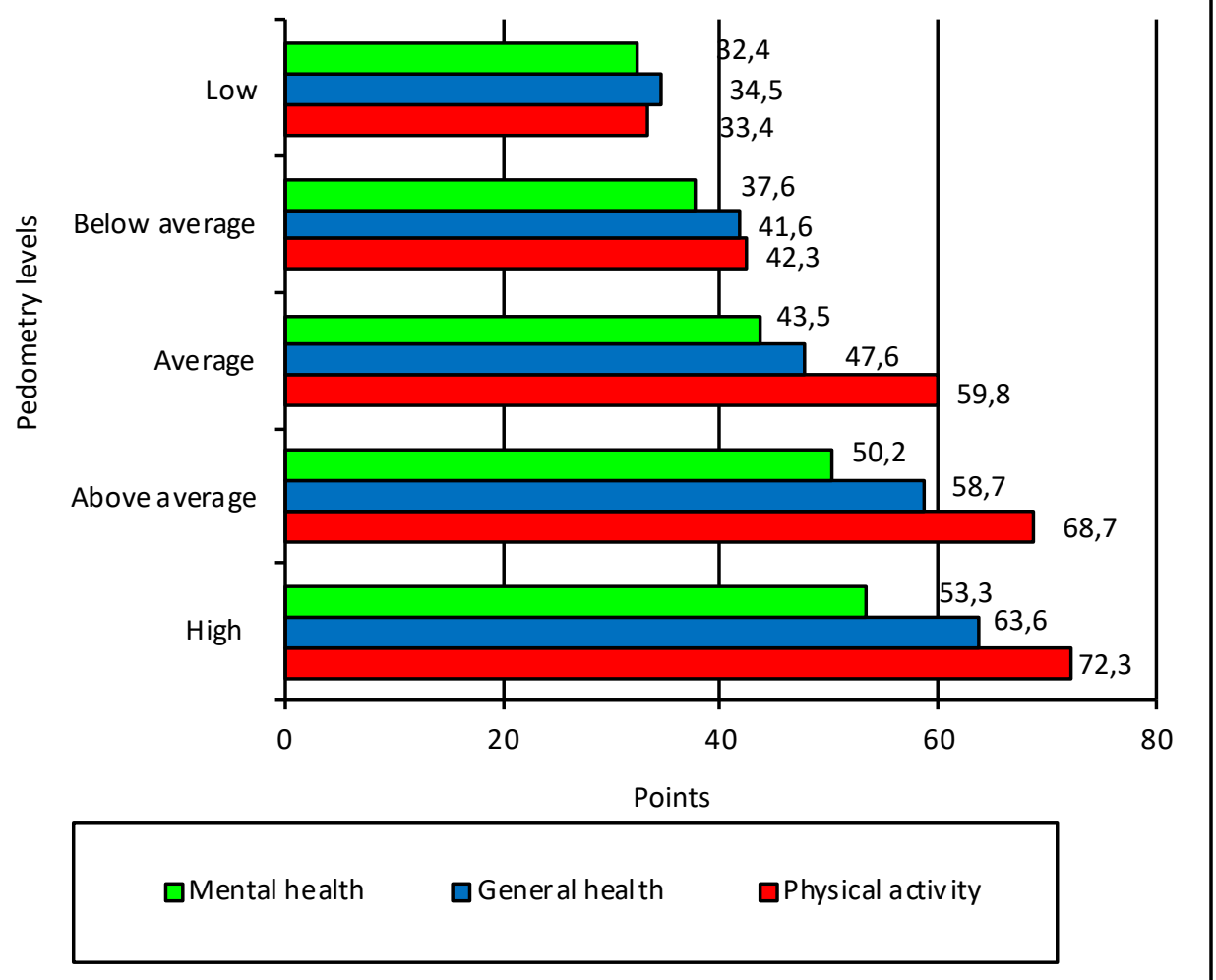

Figure 5. Life quality components of females with different levels of pedometry (in points)

pathology risk [26]. In our work, we used this method to design an estimation scale for determining the levels of students' daily pedometry.

More than half of the studied males and females have an "average" level of daily pedometry. They also have average values for life quality estimation. In addition to the step locomotions of educational and household activities, students visit fitness clubs; bicycling in summer; skiing in winter; sports and mass events at the university. Such motion activity was determined in students of St. Petersburg Humanitarian and Trade Union University [32].

Among students with "above average" and "high" levels of pedometry (high points in the life quality estimation), there are more males than females. This is compliant with the opinions of other authors about the high physical activity of the male population compared with the female population [33-35]. These males and females are constantly practicing sports. The research presents data on increasing students' interest in physical activity: at Altai University (Russia) [36, 37]; in the Republic of Belarus [38, 39]; in China [40, 41]; in Romania and Spain [42-44]; in Poland [45-46]. Confirmation is our data on the presence of high step locomotions in student-athletes.

Females with "low" and "below average" levels of daily pedometry are registered more than males. The study results of students with "low" and "below average" levels of step locomotions showed that their motor activity is limited only by locomotions in educational and household activities. The life quality of these students is estimated by low points. Other researchers have emphasized the low health condition of persons with hypodynamia in their works $[4,6]$.

The analysis of daily step locomotions of students with a "high" level of pedometry showed that they have an approximately equal number of steps per day of the week (including Sunday). The authors from Belgorod [47] emphasized the importance of the high motor activity of students on Sundays (as an obligatory element of a healthy lifestyle).

It was determined that in studied students with a "low" level of pedometry, the number of steps decreased on Sunday days compared to the working days. According to the results of the survey, these students perform only household locomotions on Sundays. Our data is confirmed by the works of authors from the Tumen region (Russia). The authors emphasize that the motor activity of some students is less than $2 \%$ of their spare time on Sundays [48].

In the studied students with an "average" level of pedometry, the number of daily step locomotions decreased slightly on Sunday days. More than $55 \%$ of such students in their answers indicated a combination of study and work. Therefore, on Sundays, they have no spare time for physical exercises or sports. This is compliant with studies done by other authors devoted to the deficit of time in working students [49].

Physical activity (as a component of life quality) shows a person's potential ability to perform physical activity. In using nordic walking in the educational process (Institute of Physical Education of the Republic of Sakha, Yakutia, Russia) is determined the increase of physical and mental components of life quality and functional indicators of the students' body [50]. Therefore, the next stage of our study 
was to study the correlation between daily pedometry and life quality (LQ) in students of a technical university.

According to our data, males, and females with "high" and "above average" levels of pedometry have the highest physical activity (89.6 and 69.9 points and 72.3 and 63.6 points, respectively). This is compliant with the results of a student survey in Nizhny Novgorod (Russia) [51]. The physical activity in students exceeds 95 points. The studied males and females with "high" and "above average" levels of pedometry have a high level of general health (69.9 and 62.8 points and 63.6 and 58.7 points, respectively) and mental health (58.8 and 59.3 points and 53.3 and 50.2 points respectively). This is compliant with the study of authors' from Minsk (the Republic of Belarus) [52]. In our opinion, such students can be attributed to the group of the safe zone of disease risk.

The "low" level of daily step locomotions of students is considered as a predictor of insufficient physical activity, low general and mental health of the person. The author from Donetsk (Ukraine) [53] and other researchers [54, $55]$ reported the influence of the physical activity level on the health condition of the human body.

In our previous survey, we found that more than $20 \%$ of them consider themselves healthy and therefore do not have to worry about their health; $37.4 \%$ have lack of willpower to take care of their health; $33.9 \%$ do not have spare time for regular physical education or sports [56].

The analysis of the students' survey answers showed that males and females with a "low" level of pedometry are indifferent to their condition and do not show concern for their health.
We confirmed that the indicators of physical activity, general and mental components of health in all females are lower than in males (Figs. 4, 5). This is compliant with the results of other authors [57-59]. The authors proved that the quality of the male population is higher in comparison with the female population.

The designed by us estimated daily pedometry scale (based on the sigma deviation method) excludes an incorrect average statistical approach to determining the volume of human step locomotions and the nature of the motor activity.

\section{Conclusions}

1. The use of the sigma deviation method allows distributing any studied population of people by the number of daily step locomotions into five sigma classes (by the level of step locomotions - "low", "below average", "average", “above average", "high"). It also allows for developing recommendations for improving the life quality of different population groups.

2. Teachers of the Physical Education Department should advise students to rationally organize the day regime with time for sports; increase the walking time. This will allow students to increase motor activity, life quality, and health.

We believe that the results of our study can be considered in the recommendations for students' adaption to the learning process and improving their life quality.

\section{Conflict of interest}

The authors declare no conflict of interest.

\section{References}

1. Bouchard C, Shephard RJ. Physical activity, fitness and health. The model and key concepts. In: Bouchard C, Shephard RJ, Stephens T. (red.). Physical Activity, Fitness and Health. International proceedings and consensus statement. Human Kinetics Publishers. Champaign; 1994. P. 77-88.

2. Tretiakov AA, Drogomeretsky VA, Agoshkov VA. Analysis of the relationship between the level of somatic health of students and motor activity. Contemporary Science and Education Problems, 2014; 3:279-285. (in Russian)

3. Basset D, Fitzhugh E, Heaz G, Erwin P, Frederick G, Wolff D. et al. Estimated energy expenditures for school-based policies and active living. American Journal of Preventive Medicine, 2013;44(2):108-113. https://doi.org/10.1016/j.amepre.2012.10.017

4. Gerber M, Ludyga S, Mucke M, Colledge F, Brand S, Puhse U. Low vigorous physical activity is associated with increased adrenocortical reactivity to psychosocial stress in students with high stress perceptions. Psychoneuroendocrinology, 2017;80:104-113. https://doi.org/10.1016/j.psyneuen.2017.03.004

5. Olafsdottir AS, Torfadottir JE, Arngrimsson SA. Health Behavior and Metabolic Risk Factors Associated with Normal Weight Obesity in Adolescents. PLoS ONE, 2016;11 (8). https://doi.org/10.1371/journal.pone.0161451

6. Hortigüela Alcalá D, Pérez-Pueyo Á, Moncada-Jiménez J. An analysis of the responsibility of physical education students depending on the teaching methodology received. Journal of Physical Education and Sport, 2015;15(2): 202-207. https://doi.org/10.7752/jpes.2015.02031

7. Yang CB, Dong MK. A Study of the correlation between teachers' teaching styles and students' participation motivation in the physical education. Journal of Baltic Science Education, 2017;16(2):199-206.

8. Zhuravlev IV. Student health: sociological analysis. Moscow: Institute of Sociology of the Russian Academy of Sciences; 2012. (In Russian)

9. Carlos Eduardo Da Costa. Motivational goals orientation in Physical Education classes of elementary education. Carlos Marco. Journal of Physical Education and Sport (JPES), 2015;15(2): 167-171.

10.Moy B, Renshaw I, Davids K. The impact of nonlinear pedagogy on physical education teacher education students' intrinsic motivation. Physical Education and Sport Pedagogy, 2016; 21(5): 517-538. https://doi.org/10.1080/17408989.2015.1072506

11.Pengpid S, Peltzer K. Sedentary Behaviour, Physical Activity and Life Satisfaction, Happiness and Perceived Health Status in University Students from 24 Countries. International Journal of Environmental Research and Public Health, 2019; 16:2084. https://doi.org/10.3390/ijerph16122084

12.Kolpakova EM. Motor activity and its effect on human health. Health, Physical Culture and Sports, 2018; 1 (8):94109. (In Russian) 
13.Liy VI, Rumba OG, Gorlov AA. Criteria and methods for investigating human motor activity (review). Theory and Practice of Physical Culture, 2013; 10:99-104. (In Russian)

14.Chan CB, Ryan D AJ, Tudor-Locke C. Health benefits of a pedometer-based physical activity intervention in sedentary workers. Prev Med, 2004;39(6):1215-1222. https://doi.org/10.1016/j.ypmed.2004.04.053

15. Wyatt HR, Peters JC, Reed GW, Grunwald GK, Barry M, Thompson H, Jones J, Hill JO. Using electronic step counters to increase lifestyle physical activity: Colorado on the MoveTM. JPAH, 2004; 1:178-188. https://doi.org/10.1123/jpah.1.3.181

16.Mynarski W, Rozpara M, Królikowska B, Puciato D, Graczykowska B. Qualitative and quantitative aspects of physical activity. Studies and Monographs, 313. Opole University of Technology; 2012. (In Polish)

17.Eakin EG, Mummery K, Reeves MM, Lawler SP, Schofield G, Marshall AJ, et al. Correlates of pedometer use: Results from a community-based physical activity intervention trial $(10,000$ Steps Rockhampton). Int J Behav Nutr Phys Act, 2007;4:31. https://doi.org/10.1186/1479-5868-4-31

18. Vilensky MYa. The basics of a student 's healthy lifestyle. Role of physical culture in health. In: The physical culture of a student. Moscow: Gardarika; 2001. P.131-174. (In Russian)

19.Savkin VV, Zyryanova VA, Pakhomova NV, Savkin NV, Trapeznikov MV. Systemic approach, indicators of health and usual motor activity in students during the performance of the valeological (health) program. Perm Medical Journal, 2011; 6 (28): 120-128. (In Russian)

20.Kiselev VI, Sharapova PH, Kulikov VP. Physical education classes and individual motor activity of students. Theory and practice of physical culture, 1991; 6:21-23. (In Russian)

21.Dragic OA, Sidorov KA. Analysis of indicators of the component composition of the body of students of URFO universities. Sports, sports and educational and patriotic activities in universities: innovations in solving topical problems: materials of the IV International Scientific and Practical Conference. Tyumen: TIU, 2018. P.85-89. (In Russian)

22.Steinerdt SV, Achkas EE. Dynamics of morphometric indicators of young men of different generations. In: Problems of Modern Human Morphology: Materials of the International Scientific and Practical Conference Dedicated to the 80th Anniversary of Professor B. A. Nikitiuk (September 25-27, 2013). Moscow; 2013. P.152-153. (In Russian)

23.Tikhvin SB, Khrushchev SV. Children's sports medicine. The management for doctors. The 2nd prod. Moscow: Medicine; 1991. River 560. (in Russian)

24.Kuchma BP, Skoblin NA. Information value of methods of assessment of physical development of children and adolescents. In: Baranova AA, Kuchma VR. (ed.) Physical development of children and adolescents of the Russian Federation. Moscow: Pediatr publishing house; 2013. P.6468. (In Russian)

25.Prusakov VM, Prusakov AB. Criteria for assessing the medical and environmental situation based on the sigmal deviation method. Hygiene and Sanitation, 2013; 1:72-76. (in Russian)

26.Conroy R. Estimation of ten-year risk of fatal cardiovascular disease in Europe: the SCORE project. European Heart Journal, 2003;24:987-1003. https://doi.org/10.1016/S0195-668X(03)00114-3

27.Yunatskaya TA, Turchaninova MS, Kozubenko OV, Turchaninov DV. Psychological component of quality of life related to health, teenagers and students of Omsk region. Basic Research, 2014;7:170-173.

28. Ware JE, Snow KK, Kosinski M, Gandek B. SF-36 Health Survey. Manual and interpretation guide. The Health institute, New England Medical Center. Boston: Mass; 1993.

29.Fiona C. Bull, Tahlia S. Maslin and Timothy Armstrong. Global Physical Activity Questionnaire (GPAQ): Nine Country Reliability and Validity Study. Journal of Physical Activity and Health, 2009; 6:790-804.

30.Godin AM. Statistics: textbook. Moscow: Dashkov and K; 2012. (In Russian)

31.World Medical Association Declaration of Helsinki: Ethical Principles for Medical Research Involving Human Subjects. JAMA, 2013;310:2191. https://doi.org/10.1001/jama.2013.281053

32.Sokolova EVE. Analysis of motor activity of SPBGUP students during the school year. Physical Education and Sports Training, 2019; 1 (27): 35-42. (in Russian)

33.Kudyashev NH, Bolgov VN, Kudyasheva AN. Application of interfacing tables for analysis of students "attitude to physical culture in educational-mass and sports work of the university. Basic researches, 2015;2(18):4004-4007. (In Russian)

34.Gorelov AA, Gavrishova EV. Comparative study of the nature of motor activity and mental efficiency of students of different specializations. Bereginya; 2013. (In Russian)

35.Jagiello W, Wolska B, Sawczyn S, Dornowski M. The similarity of training experience and morphofunctional traits as prediction criteria of the sports level in subsequent stages of long-term women's judo training. Archives of Budo. 2014;10:201-210.

36.Denisova GS. Dependence of body weight of students of special department of Altay State University on the nature of nutrition and optimal level of motor activity. Health, Physical Culture and Sports, 2019;1(12):127-152. (In Russian)

37.Golovin SM, Romanova EV. Sports self-determination of university students. Health, Physical Culture and Sports, 2017;3(6): 3-12. (In Russian).

38.Savko EI, Hojempo SV. Student youth and their attitudes to physical culture, and healthy lifestyles. Health, Physical Culture and Sports, 2018;4 (11): 62-76. (In Russian)

39.Spakov AI, Krumina LP, Mischenko AN, Obelevsky AG, Pavluti OV. Self-assessment of students 'motor activity and their attitude towards physical education organization (comparison of research data in 2005 and 2015). In: Healthsaving technologies and systems: psycho-pedagogical and medical-biological aspects, materials of the II International Scientific and Practical Conference on May 20, 2016. Baranovichi; 2016. P.215-219. (in Russian)

40.Zhang Z, Chen B, Chen W. The mediating effect of perceived health on the relationship between physical activity and subjective well-being in Chinese college students. Journal of American College Health, 2019:1-8. https://doi.org/10.1080/07448481.2019.1645676

41.Xu F, Wang X, Xiang D, Wang Z, Ye Q, Ware RS. Awareness of knowledge and practice regarding physical activity: A population-based prospective, observational study among students in Nanjing, China. PLoS ONE, 2017;12:e0179518. https://doi.org/10.1371/journal.pone.0179518

42.Zurita-Ortega F, Badicu G, Chacón-Cuberos R, CastroSánchez M. Motivational Climate and Physical Activity: A Multigroup Analysis in Romanian and Spanish University Students. International Journal of Environmental Research and Public Health, 2019;16:2013. https://doi.org/10.3390/ijerph16112013 
43.Potop V, Timnea OC, Stanescu M. Improving sports technique of stretched Gienger salto on uneven bars based on biomechanical indicators. Modern Journal of Language Teaching Methods, 2017;7(8):472-480. https://doi.org/10.2991/icmmse-17.2017.64

44.Potop V, Timnea O, Stănescu M. Correlative analysis of the kinematic and dynamic characteristics of sports technique used in acrobatic elements and performances achieved by junior gymnasts in balance beam events. Conference proceedings, Volume 17. Informatics, Geoinformatics and Remote Sensing, 2017; 21: P. 231-238. https://doi.org/10.5593/sgem2017/21

45.Kalina RM, Jagiello W. Non-apparatus, Quasi-apparatus and Simulations Tests in Diagnosis Positive Health and Survival Abilities. In: Ahram T, editor. Advances in Human Factors in Sports, Injury Prevention and Outdoor Recreation, Ahfe 2017. Advances in Intelligent Systems and Computing. 2018; 603: 121-128. https://doi.org/10.1007/978-3-319-60822-8_12

46.Klimczak J, Kalina RM, Jagiello W. Fun forms of martial arts in diagnosing and reducing aggressiveness - mental effects of a one-day course for Polish animators of sport. In: Kalina RM, editor. 1st World Congress on Health and Martial Arts in Interdisciplinary Approach (HIMA), Location: Univ Sch Phys Educ Wroclaw, Czestochowa, Poland; 2015. P. 187189.

47.Gorelov AA, Tretiakov AA. Nervous-emotional tension and methods to increase students 'resilience to its effects. Belhorod: CPI Politicra; 2012. (In Russian)

48.Kozlov AV, Pasko GV. Optimal motor regime as a mandatory factor of healthy lifestyle of students. In: Sports, sports and educational and patriotic activities in universities: innovations in solving topical problems: materials of the IV International Scientific and Practical Conference. Tyumen: TIU; 2018. P. 111-113. (In Russian)

49.Myltasova OV, Konstantinov AJ. Combining work and study: Do funds always justify the goals? Modern scientific research and innovation, 2016; 6:11-20. (In Russian)

50.Korkin EV, Krysyuk OB. Impact of Nordic walking classes on performance and quality of life of students of physical education university. Physical Culture: Education, Training, 2017; 1:51-53. (in Russian)

51.Sidorov DG. Problems of formation of healthy-oriented process of education in the university. Problems and prospects for the development of physical culture in Russia and near-abroad countries: a collection of scientific articles. Barnaul; 2010. P. 225-230. (In Russian)

52.Zelezinsky GA, Korenko PN, Kravchenok MA, Sallum AI. Quality of life for medical students and clinical residents. Clinical medicine, 2005;8:29-31. (In Russian)

53.Krasnozhon SV. Motor activity as a criterion of health level. Physical culture. Sport. Tourism. Motor Recreation, 2017; 2 (1): 46-52. (In Russian)

54.Stamatakis E. Screen based entertainment time, allcause mortality and hospital events follow-up. J. of the Amer. College of Cardiology, 2011; 57(3):292-299. https://doi.org/10.1016/j.jacc.2010.05.065

55.Oyeyemi AL, Oyeyemi AY, Adegoke BO, Oyetoke FO, Aliyu HN, Aliyu SU, et al. The short international physical activity questionnaire: cross-cultural adaptation, validation and reliability of the Hausa language version in Nigeria. BMC Med Res Methodol, 2011;11:156. https://doi.org/10.1186/1471-2288-11-156

56.Kolokoltsev MM, Ambartsumyan RA. Characteristics of valeological installation in young men Pripikayalia. Problems of Modern Pedagogical Education, 2018; 62(4):96-98.

57.Jamali A, Tofangchiha S, Jamali R, Nedjat S, Jan D, Narimani A, et al. Medical students' health-related quality of life: roles of social and behavioural factors. Med Educ, 2013;47:1001-12. https://doi.org/10.1111/medu.12247

58. Voltmer E, Rosta J, Aasland OG, Spahn C. Studyrelated health and behavior patterns of medical students: a longitudinal study. Med Teach., 2010;32(10):422-428. https://doi.org/10.3109/0142159X.2010.496008

59.Hagstromer M, Ainsworth BE, Pekka O, Sjostrom M. Comparison of a Subjective and an Objective Measure of Physical Activity in a Population Sample. Journal of Physical Activity and Health, 2010;7: 541-550. https://doi.org/10.1123/jpah.7.4.541 
Information about the authors:

Mikhail M. Kolokoltsev; (Corresponding author); Doctor of Medical Sciences, prof.; http://orcid.org/0000-0001-6620-6296; mihm49@mail.ru; Irkutsk National Research Technical University; Irkutsk, Russia.

Elena V. Romanova; https://orcid.org/0000-0003-4317-605X; romanovaev.2007@mail.ru; Department of Physical Culture, Altay State University; Barnaul, Russia.

Wladyslaw Jagiello; Doctor of Sciences, prof.; http://orcid.org/0000-0001-7417-4749; wjagiello1@wp.pl; Department Combat Sports and Personal Training, Gdansk University of Physical Education and Sport; Kazimierza Górskiego 1, 80-336 Gdańsk, Poland.

Tetiana S. Yermakova; Doctor of Pedagogical Sciences; assistant prof.; http://orcid.org/0000-0002-3081-0229; yermakova2015@gmail.com; Kharkiv State Academy of Design and Arts; Kharkiv, Ukraine.

Cite this article as:

Mikhail M. Kolokoltsev, Elena V. Romanova, Wladyslaw Jagiello, Tetiana S. Yermakova. The estimation scale of the daily pedometry of senior students. Physical education of students, 2020;24(2):100-108. https://doi.org/10.15561/20755279.2020.0205

This is an Open Access article distributed under the terms of the Creative Commons Attribution License, which permits unrestricted use, distribution, and reproduction in any medium, provided the original work is properly cited http://creativecommons.org/licenses/by/4.0/deed.en

Received: 02.03.2020

Accepted: 15.04.2020; Published: 30.04.2020 